Supporting Information

\title{
Acidic deep eutectic solvents as hydrolytic media for cellulose nanocrystal production
}

Juho Antti Sirviö*, Miikka Visanko, and Henrikki Liimatainen

Fibre and Particle Engineering Research Unit, University of Oulu, P.O. Box 4300, FI-90014,

Finland.

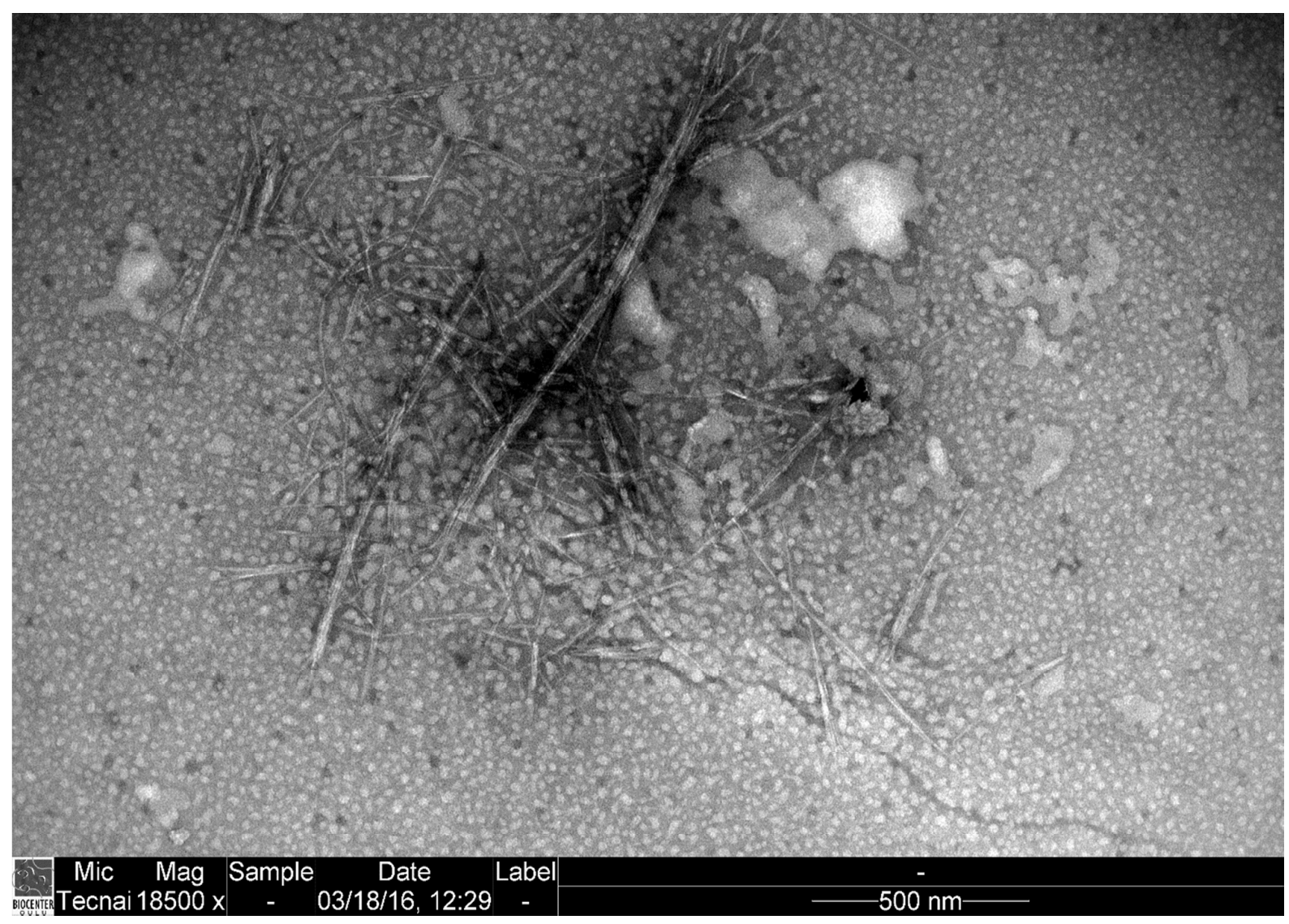



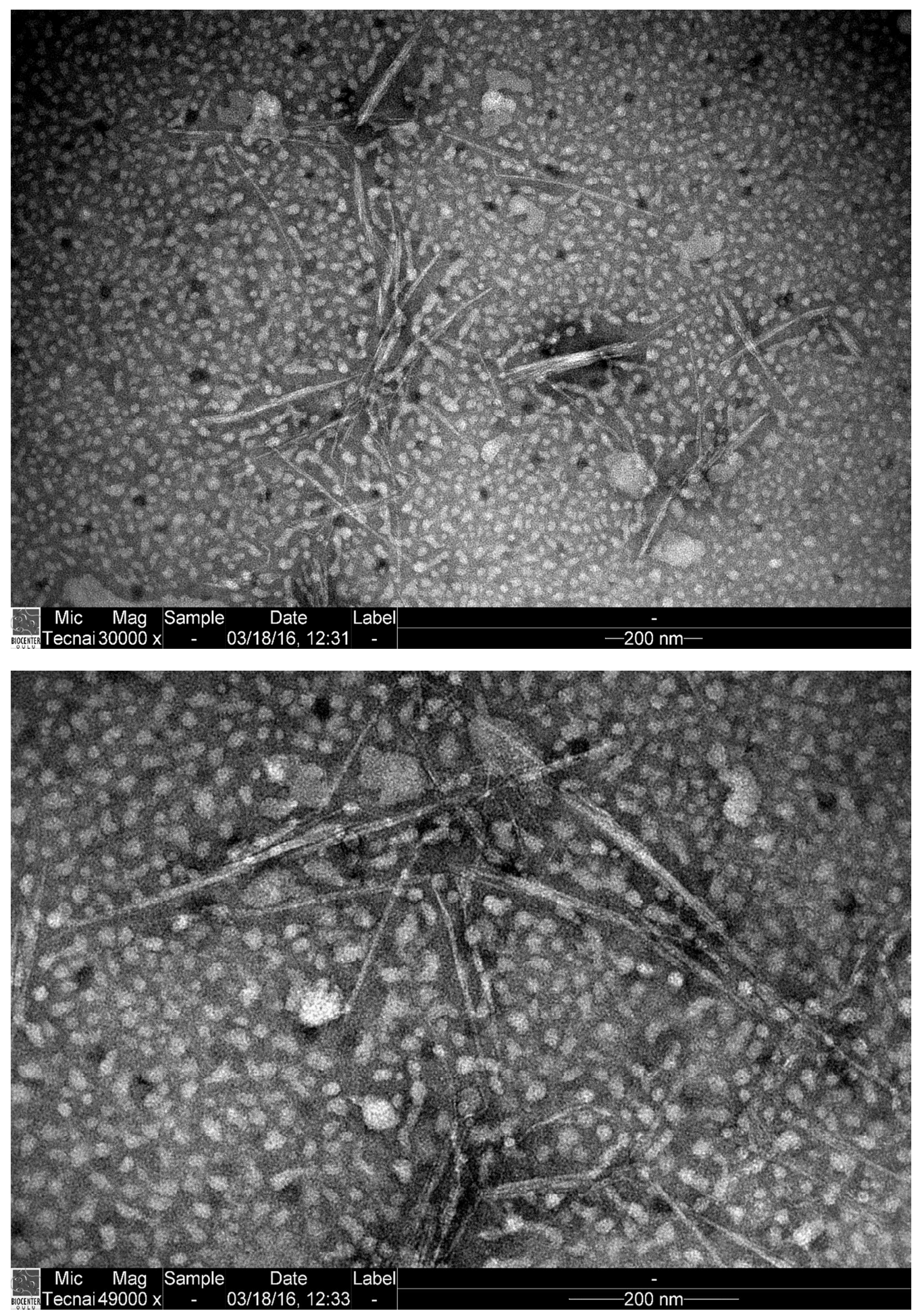
Figure S1. TEM images of CNCs obtained from DES2-pretreated cellulose fibers

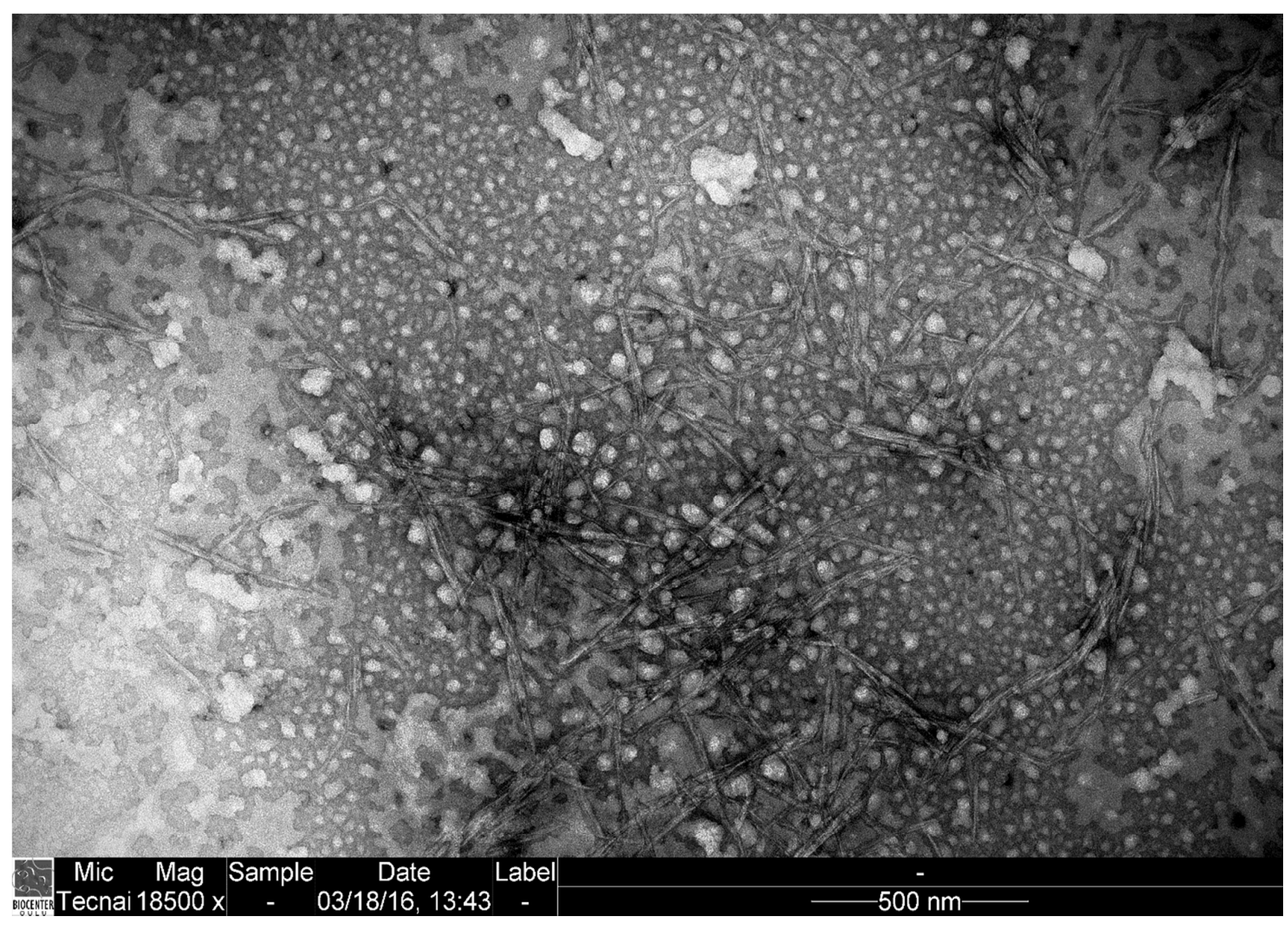



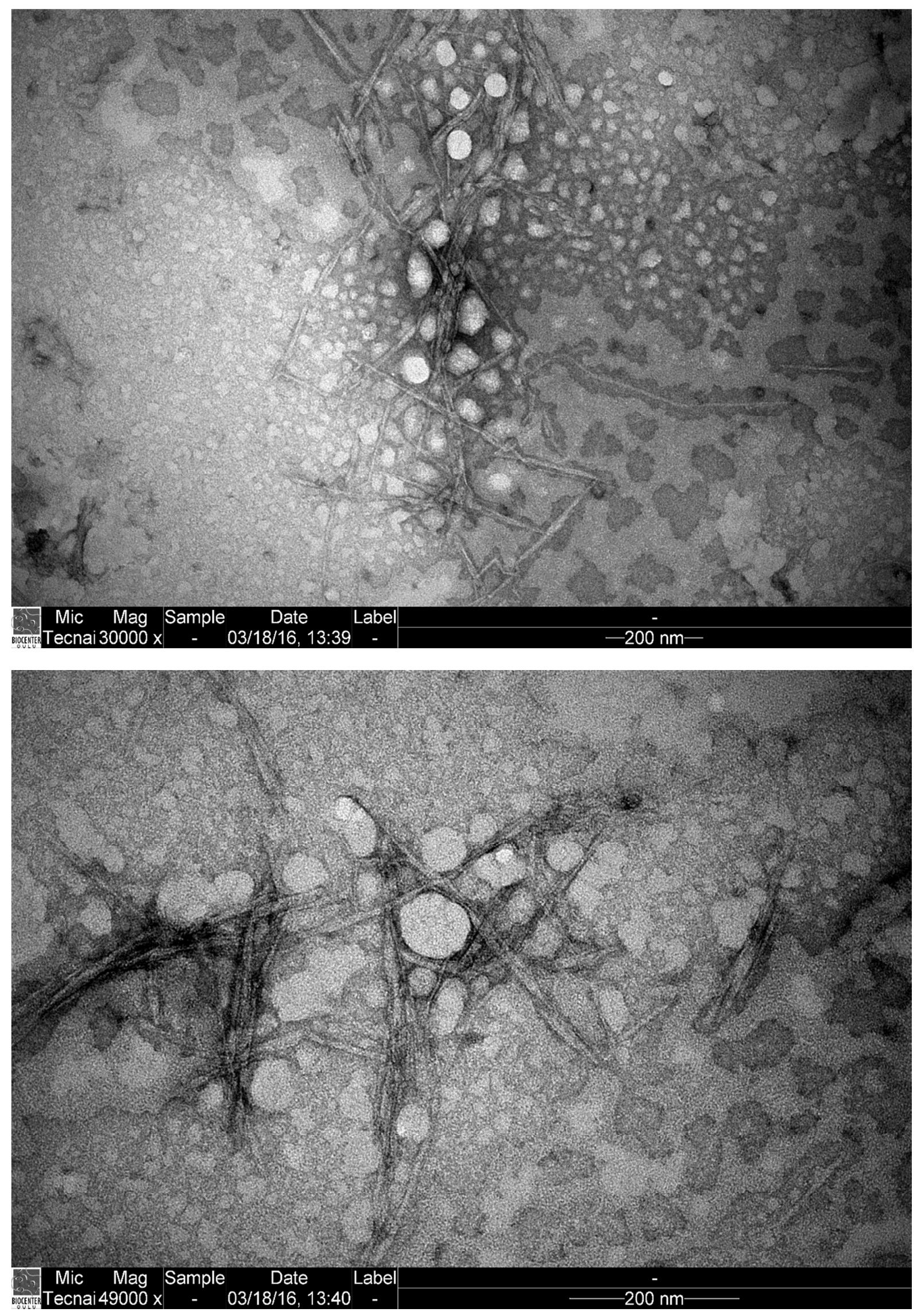
Figure S2. TEM images of CNCs obtained from DES3-pretreated cellulose fibers

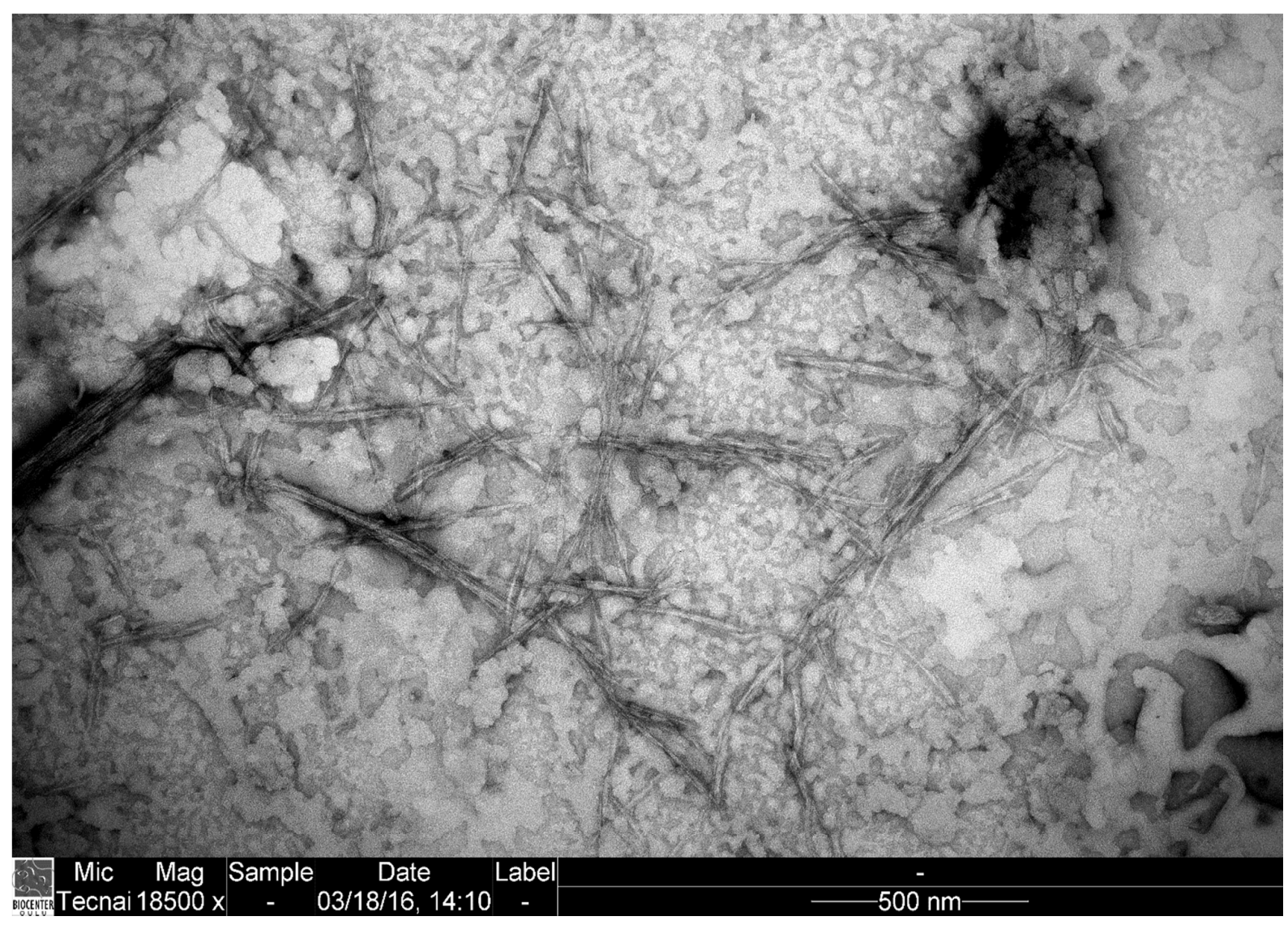



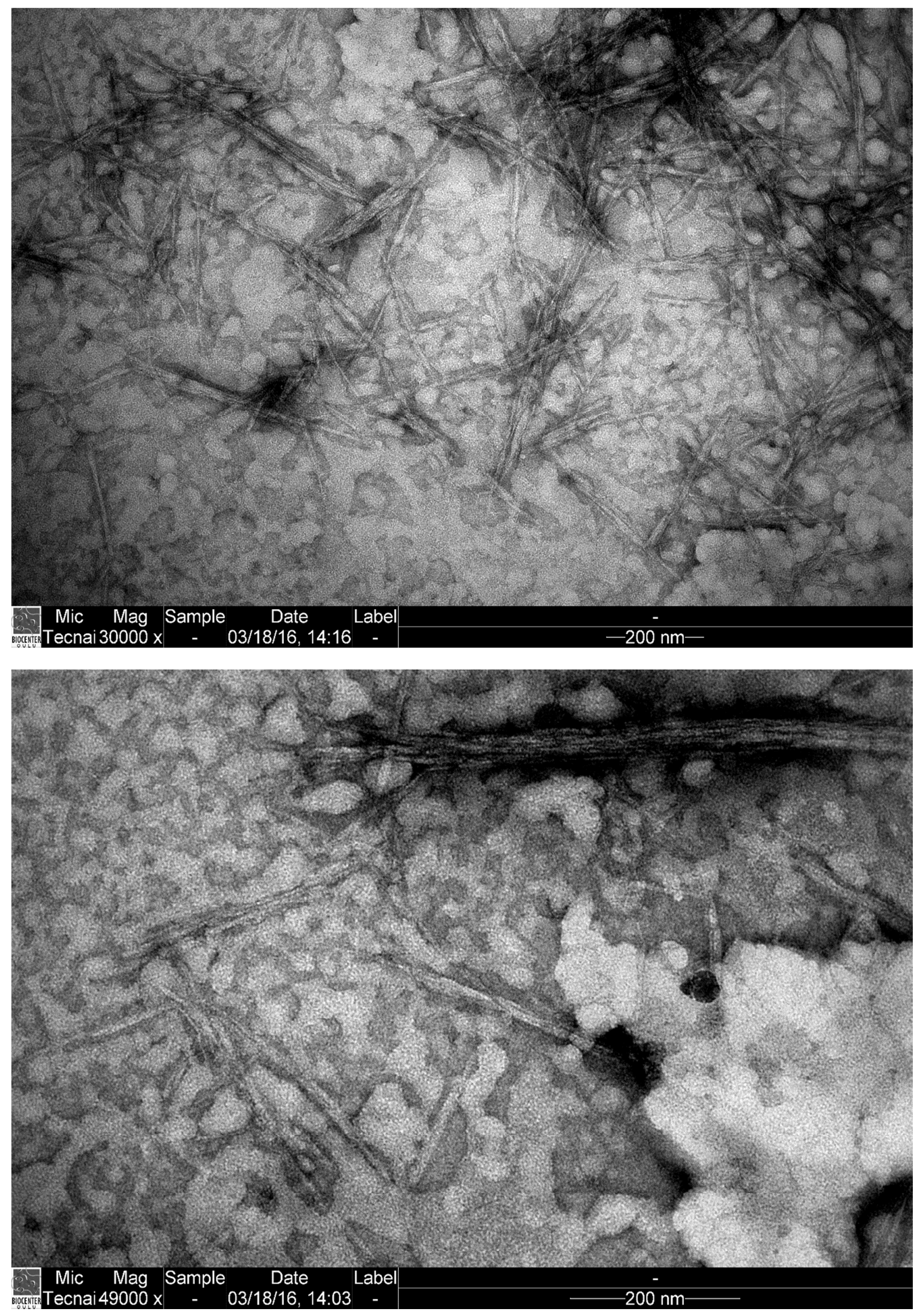
Figure S3. TEM images of CNCs obtained from DES4-pretreated cellulose fibers

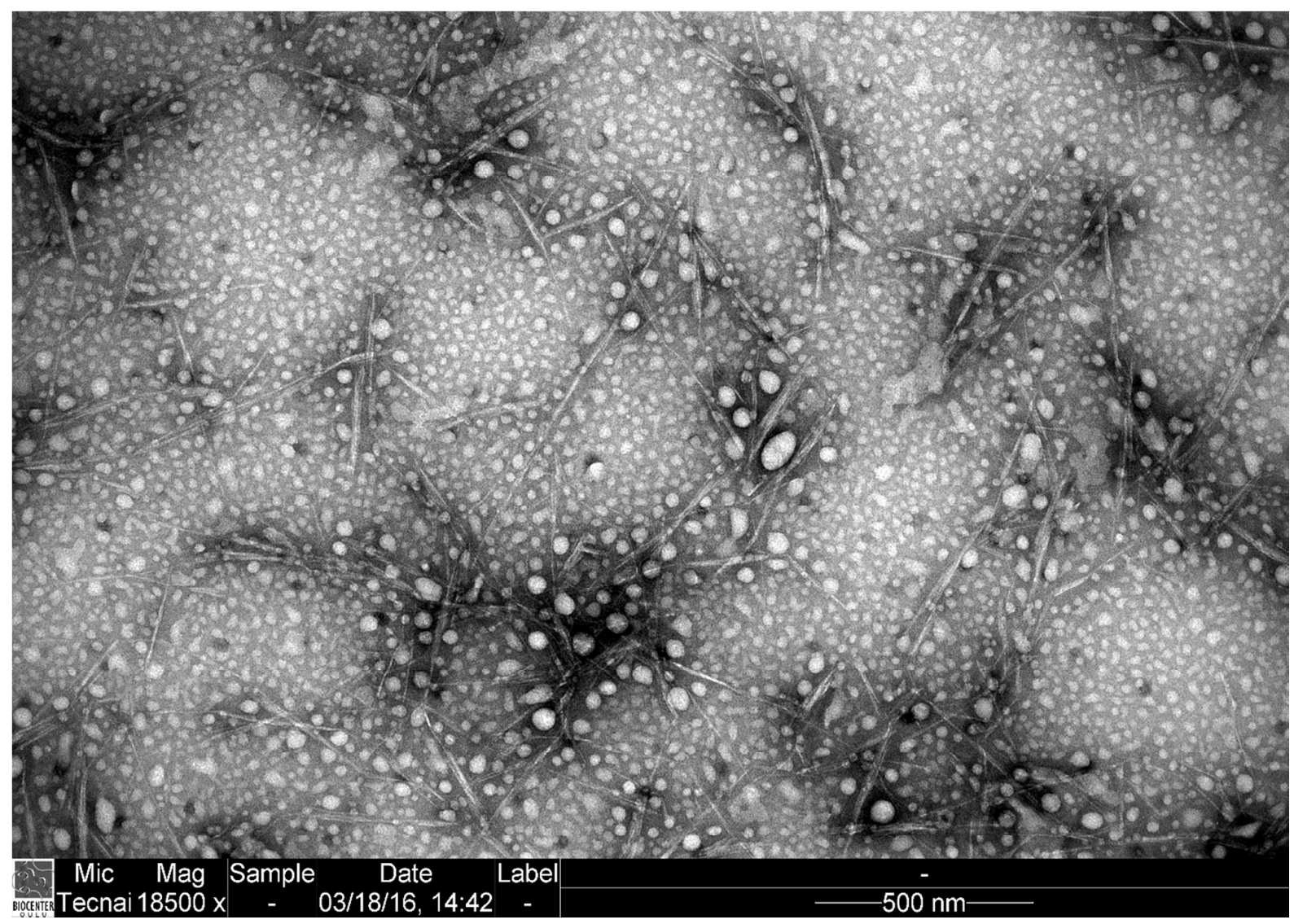



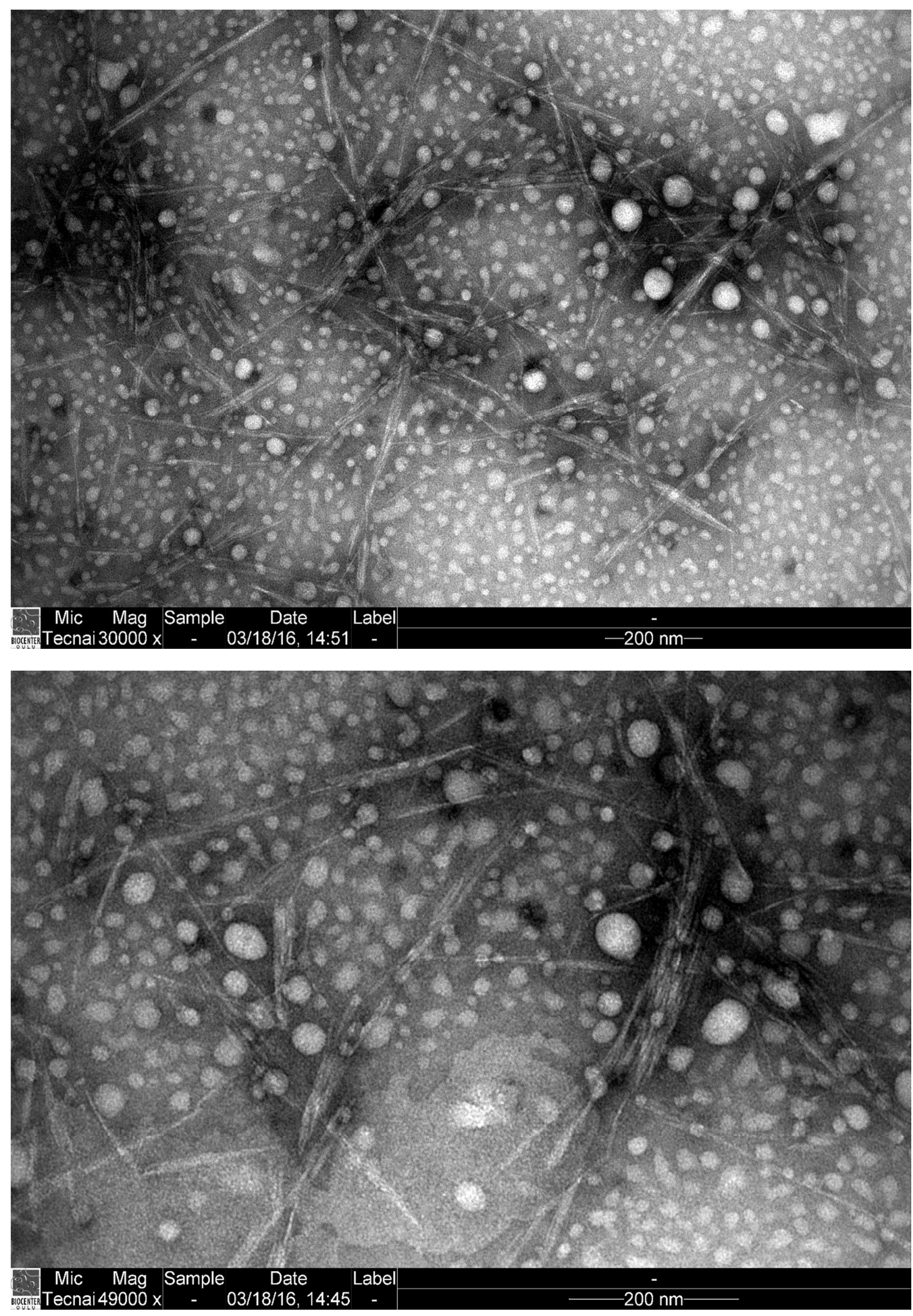
Figure S4. TEM images of CNCs obtained from DES4-pretreated cellulose fibers 